T. OTANi*, A. TSUYUKI, T. IWACHI, S. SOMEYA, K. TATENO, H. KAWAi, T. SAITO, K. S. KANYIVA, T. SHIBATA* (WASEDA UNIVERSITY, TOKYO, NATIONAL INSTITUTE OF TECHNOLOGY ANAN COLLEGE, TOKUSHIMA AND TOKYO UNIVERSITY OF SCIENCE, JAPAN)

Facile Two-Step Synthesis of 1,10-Phenanthroline-Derived Polyaza[7]helicenes with High Fluorescence and CPL Efficiency

Angew. Chem. Int. Ed. 2017, 56, 3906-3910.

\section{Fluorescent, CPL-Active Aza[7]helicenes in Two Steps}

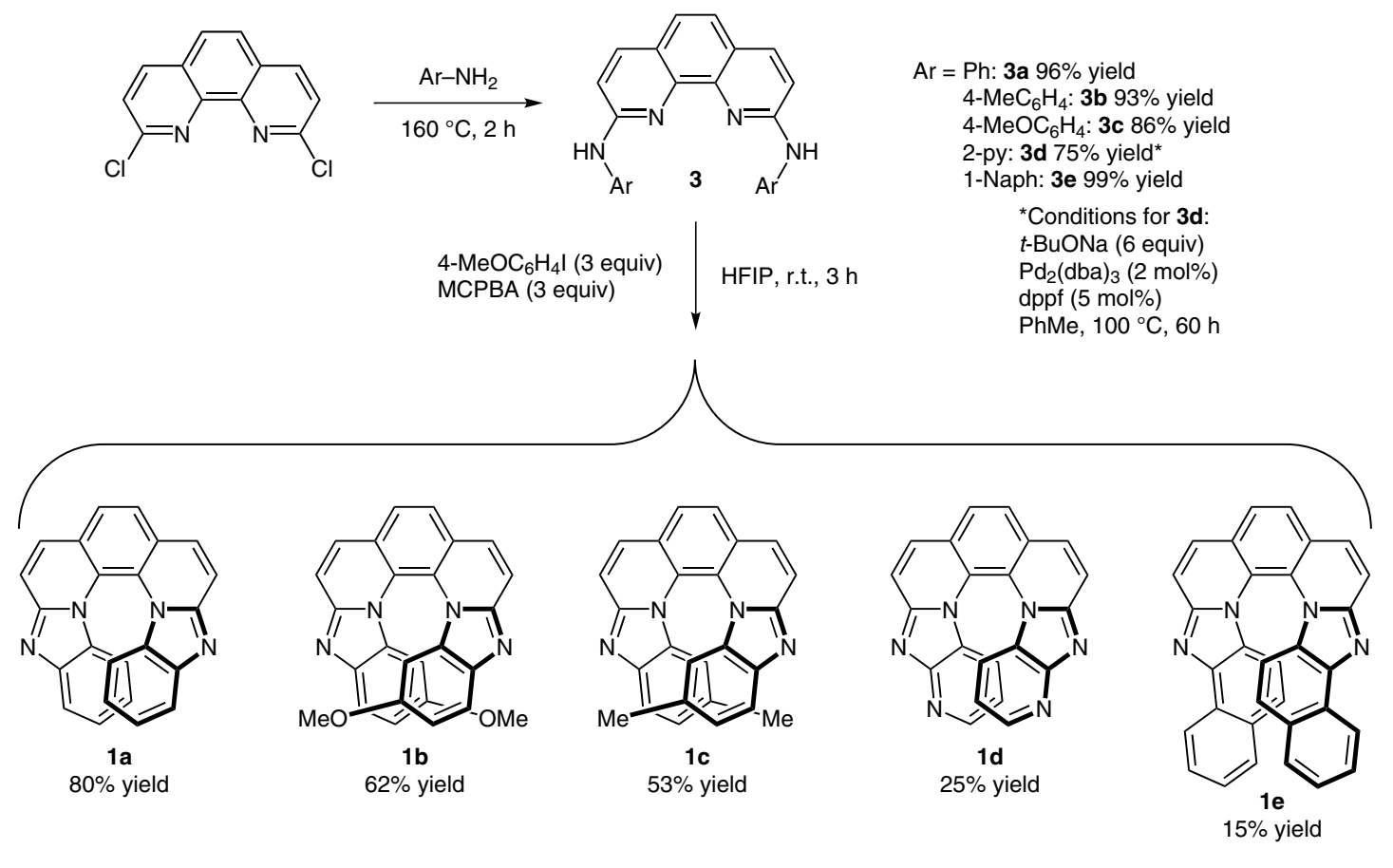

Significance: Helicenes are molecules comprised of ortho-fused aromatic rings. They have potential applications in circularly polarized luminescence (CPL) emitting materials because some helicenes show high CPL activities. However, the fluorescence quantum yields of helicenes are generally low because the inherent curved $\pi$-systems promote rapid intersystem crossing from the singlet to the triplet states. Herein, Shibata and co-workers report a series of aza[7] helicenes that possess both high fluorescence and CPL activity, which make these molecules an appealing CPL-emitting material.
Comment: The authors report a facile two-step synthesis of aza[7]helicenes. The quantum yield of 1a (0.39) was comparable to the highest value of acid enhanced the quantum yield of $\mathbf{1 a}$ to 0.80 . Although the value of the luminescence dissymmetry ratio $g_{\text {lum }}$ of $\mathbf{1 a}$ decreases slightly upon addition of acid (0.009 at $473 \mathrm{~nm}$ to 0.008 at 514 $\mathrm{nm})$, this molecule remains an attractive CPLemitting material. Single-crystal $\mathrm{X}$-ray analysis and DFT calculations on 1a were also conducted. among reported [7] helicenes (0.40). The addition

\section{Category}

Synthesis of

Materials and

Unnatural Products

\section{Key words}

azaaromatics

fluorescence

circular dichroism

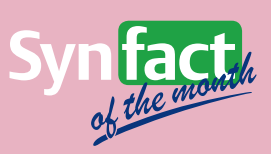

